\title{
APRESENTAÇÃO
}

\section{Dossiê: Mercado, Mídia e Consumo}

\section{Marcia da Silva Mazon Maria Chaves Jardim ${ }^{2}$}

Como estudar os mercados no século XXI? Quais as alternativas para entender como as pessoas consomem, quais os seus gostos e como elas acessam o que desejam consumir? E quais mudanças estes processos provocam assim como são provocados na sociedade, nos modos de sociabilidade? Como se produzem as crenças difundidas via algoritmos de mídias sociais e aplicativos e que estão disponíveis para consumidores deste mercado? Em que medida essas crenças difundidas pelas mídias sociais e pelos aplicativos de relacionamento são incorporadas ou sofrem resistências dos consumidores de produtos, de serviços e de valores? Quem são os agentes e as instituiçôes que estão por trás das mídias sociais e dos aplicativos? Qual a mágica realizada pelos algoritmos e como ela é performatizada nas redes sociais e nos aplicativos? Qual a relação que o Estado estabelece com estes dispositivos?

O fenômeno das mídias sociais e dos aplicativos nos instigam diversas questôes. A proposta deste Dossiê é apresentar um conjunto de pesquisas

\footnotetext{
I Doutora em Sociologia Política pela Universidade Federal de Santa Catarina (UFSC, Florianópolis, SC, Brasil) é professora associada do Departamento de Sociologia e Ciência Política na mesma Universidade, do Programa de Pós Graduação em Sociologia e Ciência Política e coordena o Núcleo de Sociologia Econômica (Nusec).

2 Professora Livre Docente do Departamento de Ciências Sociais da Universidade Estadual Paulista Júlio de Mesquita Filho (UNESP). Campus de Araraquara. E-mail:majardim@fclar.unesp.br
}

$(\mathrm{cc}) \mathrm{Br}$
Direito autoral e licença de uso: Este artigo está licenciado sob uma Licença Creative Commons. Com essa licença você pode compartilhar, adaptar, para qualquer fim, desde que atribua a autoria da obra, forneça um link para a licença, e indicar se foram feitas alterações. 
teóricas e empíricas sobre o tema, de forma a buscar uma primeira aproximação com esse novo fenômeno, que, em alguma medida, ressignifica as relaçôes de mercado, de consumo e de sociabilidade.

Quando falamos de mercados, isso implica que atores interessados em vender encontrem-se com aqueles interessados em comprar; a partir do acordo de preço, qualidade e condiçóes de entrega,realiza-se o ato de transferência de direitos de propriedades dos primeiros para os segundos. Estaé a definição do mercado; porém, este encontro é sempre povoado por relaçôes de poder, assimetrias informacionais e necessariamente preenchido pela construção de significados sempre cambiantes.

Fala-se dos gostos e dos bens de consumo como parte constituinte dos estilos de vida - um conjunto de práticas e de consumos que tende a ser adotado pelo mesmo grupo e que expressa relaçóes de pertencimento a uma classe social, ou o que Max Weber chamou a "própria estilização da vida". Os agentes tendem a ter gostos relacionados com suas condiçóes econômicas, o gosto é um marcador de classe e é um produto do mesmo princípio: o habitus. Nas últimas décadas, o tema das mídias sociais tornou-seum convite ao debate da Sociologia dos Mercados: as vendas online, os algoritmos, o espaço público e privado do Facebook e do WhatsApp respectivamente mostram como a vida online e off-line se constituem e reconstituem em processos dinâmicos, que afetam e são afetados pela vida social e pela vida digital.

O contexto nos inspira novas questóes: a ameaça das vendas online sobre lojas físicas, bem como a perda de postos de trabalho; o surgimento de novas formas de dominação no mercado de trabalho digital, muitas vezes eufemizadas no discurso de flexibilidade e de empreendedorismo; a construção de novas formas de relacionamentos pelas mídias sociais e dos aplicativos, por meio dos quais se consomem afetos e também desafetos.

Como desdobramento, o conceito de mercado tem sido reelaborado empiricamente, assim como a ideia de consumidor. No uso efetivo das mídias sociais e dos aplicativos para realizar trocas e consumos (econômicas, afetivas, sexuais, de valores), o consumidor do século XXI tem construído novas subjetividades ( habitus), novas formas de engajamento, em alguma medida influenciadas pelos algoritmos das mídias e dos aplicativos. Esses 
algoritmos, por sua vez, são produzidos por agentes e instituiçóes historicamente datadas, que estão em disputa não apenas por valores numéricos, mas ainda e, sobretudo, pela produção de narrativas e pela definição de um sentido para o mundo social, ou seja, a doxa, no sentido aplicado por Pierre Bourdieu. Com o consumo "espontâneo" das mídias e dos aplicativos, corre-se o risco de performatizar valores e crenças prescritas pelos empreendedores digitais.

Portanto, a Sociologia dos Mercados está diante de um novo contencioso. Este Dossiê busca contribuir para o entendimento desse fenômeno, acolhendo pesquisas que, a partir da ideia de mercado, mídias sociais e consumidor, busquem entender as interações entre espaços públicos, privados, virtuais e corporativos; abordem as relaçóes de trabalho, e de dominação no mundo digital; interessem-se pelo consumo de afetos por meio das trocas digitais; tratem os agentes e as instituiçóes das mídias digitais como atores em permanente disputa pelo poder; considerem as novas formas de sociabilidades, sem negar a capacidade de os consumidores ressignificarem os condicionantes virtuais. Enfim, os artigos aqui apresentados pretendem contribuir para o entendimento dos agenciamentos e das resistências na construçáo do conceito de mercado e de consumidor do século XXI, considerando que estes estão em constante interação com as mídias sociais, sem negar as formas já existentes de consumo.

Este dossiê é apresentado no ano em que comemoramos dezanos do Grupo de Trabalho de Sociologia Econômica presente nos Congressos da Sociedade Brasileira de SociologiaSBS (e que igualmente está presente na Associação Nacional de Pos-Graduação e Pesquisa em Ciências Sociais -ANPOCS) e que reúne pesquisadores de diferentes estados brasileiros, tão bem como colaboradores da América Latina e França. Um colaborador que acompanha a Sociologia Econômica brasileira desde seus primeiros movimentos é Philippe Steiner. E é com um artigo dele que abrimos este Dossiê.

$\mathrm{O}$ artigo de Steiner discute uma nova abordagem da economia, a partir do conceito de match. Matching significa que existem algumas questôes específicas relacionadas à associação efetiva de um determinado recurso a uma determinada pessoa. $\mathrm{O}$ match pode, portanto, parecer uma extensão da questão tradicional relacionada à distribuição da riqueza; contra essa 
aparência, o presente artigo enfatiza que algo mais está em jogo quando se trata de entender como o match é realmente implementado. $\mathrm{O}$ artigo explora esta ideia, a partir do conceito de pastorado da obra de Michel Foucault; da ênfase às mudanças trazidas pela enorme quantidade de dados e a tecnologia necessária para implementar uma nova forma de governamentalidade, aquela em que, na esteira do antigo preceito religioso, requer que o líder governe a população como um todo, e cada indivíduo em particular ("omnes et singulatim" nos termos de Foucault). Paraassimilaro novo fenômeno, Steiner reivindica uma Sociologia Econômica da informação cujo objetivo seria compreender as informaçóes que circulam por trás dos algoritmos, entre ofertante e demandante.

Com forte inspiração nos argumentos de Steiner, o segundo artigo, de Maria Chaves Jardim, trata do mercado de afeto, influenciado pela chegada dos aplicativos para relacionamento, e busca identificar os elementos que ajudam a compor a mágica dos algoritmos afetivos. Com base em diversas estratégias metodológicas (etnografia do Tinder, pesquisa empírica com mulheres entre 35-47 anos e observação participante em uma página fechada do Facebook), Jardim demonstra que a cultura do amor romântico alimenta o mercado de aplicativos, este que, por sua vez, precisa de mercados paralelos para funcionar, como o mercado de autoajuda afetiva. Nesse sentido, a autora defende que a "fórmula do amor", criada pelos matemáticos e inserida nos smartphones, não existe em um vácuo social; a crença no amor romântico e a illusio(no sentido de Pierre Bourdieu)do casamento como ideário de felicidade ajudam, em diálogo com o mercado de autoajuda, a sustentar o mercado de afeto virtual.

$\mathrm{Na}$ sequência, dois artigos abordam a relação mercado e natureza: Marina Sartore e Brian Coffey, que analisam os quiosques de praia;AnnePinto Brandalise e Elaine da Silveira Leite, autoras que estudam a construção do seguro ambiental no Brasil.

O artigo de Marina Sartore e Brian Coffey compara as avaliaçóes escritas do TripAdvisor (AET) sobre quiosques de praia no Brasil e na Austrália. $\mathrm{O}$ argumento do artigo é o de que as AET são uma fonte útil da expressão de diferenças nas representaçóes coletivas da beira da praia. $\mathrm{O}$ artigo conclui que taisrepresentaçóes coletivas diferem pelas categorias de tempo 
e espaço. Estes autores observam que a compreensão das diferentes representaçóes coletivas da beira da praia produz conhecimento de suporte para as políticas públicas a enfrentar desafios contemporâneos no litoral, como a busca pelo equilíbrio entre o desenvolvimento comercial e a conservação da natureza.

Anne Pinto Brandalise e Elaine da Silveira Leite, seguindo de perto os trabalhos de Viviana Zelizer nos EUA, analisam a construção social do mercado dos seguros ambientais no Brasil. A partir da análise documental das leis referente à Política Nacional de Proteção Ambiental, entrevistas e material corporativo e publicitário de três seguradoras, as autoras exploram as justificativas empresariais que preenchem de significados este mercado, assim como a recepção e acomodação cultural do seguro ambiental.Os resultados apontam que o mercado de seguros ambientais tem transformado o risco ambiental em um produto de mercado; para tanto, o mercado cria dispositivos de classificação dos riscos ambientais e incorpora um conjunto de práticas de avaliaçáo e valoração determinadas como seguras pela sociedade. Assim, na busca por vender a segurança, o mercado de seguros ambientais tem construído um conjunto de virtudes morais, que por sua vez, passam a fazer parte do discurso sobre proteção ambiental.

Abordando mercados e seus prescritores, temos os artigos de Marcia da SilvaMazon sobre a indústria farmacêutica e de Ernesto Lima Neto e Marcelo Carneiro sobre a produçáo de queijos.

O primeiro artigo, de Marcia da Silva Mazon, investiga a relação entre psiquiatras como prescritores da saúde e o consumo de medicamentos produzidos pela indústria farmacêutica na emergência dos neurolépticos voltados para a infância. Esta autora observa a particularidade do consumo de medicamentos especiais como os neurolépticos: diferentemente de outros bens de consumo,são consumidospor procuração, supóem a prescrição de receita por parte do profissional da medicina. A partir de revisão bibliográfica e análise documental, a autora discute os pontos de aproximaçáo entre psiquiatras e a industria farmacêutica a partir das reformas liberalizantes da década de 1990 no Brasil. Segundo Mazon, no cerne das transformaçóes recentes da reforma da psiquiatria e dos processos de medicalização - em particular, a partir da publicação do Manual Diagnóstico e Estatístico de Transtornos 
Mentais (DSM) na sua quinta versão - a psiquiatria se reinventoucomo especialidade e mobilizouo discurso da prevenção, como prevenção medicalizada da infância e o hospital perdeuespaço para a indústria farmacêutica.

O artigo de Evaristo José de Lima Neto e Marcelo Sampaio Carneirodiscute o processo de estabelecimento de um padrão de qualidade sanitária na cadeia produtiva de leite bovino na região de Imperatriz no Maranhão, analisando a disputa entre duas formas de produção diferentes, representadas pela indústria de laticínios e por produtores informais de queijo (as chamadas queijeiras). Estes autores observam a constituição de duas convenções de qualidade nessa cadeia produtiva, identificadas como uma convenção de tipo industrial e uma convenção de natureza doméstica, destacando a disputa pelos produtores de leite, mas indicando igualmente a possibilidade do estabelecimento de alguns tipos de compromissos entre essas diferentes convençóes.

Ainda sobre dispositivos, Ana Carolina Bichoffe e Mateus Baeta Diógenes reforçam as dimensóes cultural e transnacional dos dispositivos, com foco nos dispositivos do mercado financeiro. A partir de uma inspiraçáo foucaultiana, que aponta a existência de relaçôes de força e de "efeitos de verdade" nos dispositivos de mercado, os autores argumentam que o Estado contemporâneo, foco de poder dos dispositivos, estaria, ele mesmo, se tornado alvo destes dispositivos. Concretamente, os autores defendem que o Estado (sociedade e jogo político-financeiro nacional) tem incorporado os dispositivos classificatórios com uma verdade inquestionável. Assim, a institucionalização e a racionalização específica do risco financeiro, não através de enfrentamentos, mas pela dominação performática, tem se tornado um caminho seguro aos Estados Contemporâneos. Ao recorrer aos dispositivos promissores e sustentáveis para resolver problemas societais, traduzindo-os em regras de conduta, assegurando a adesão a essas regras e, quando necessário, ajustando essas regras às circunstâncias em mudança, o Estado tem criado a institucionalização e racionalização do risco financeiro, orientado por um novo tipo de poder disciplinar específico, de intervenção e controle social. Como desdobramento, o próprio Estado tem se curvado a essa estrutura de poder.

O artigo de Ana Lúcia de Castro tem como universo empírico um bairro localizado na periferia de Santo André, no município da Grande 
São Paulo, onde a autora realizou pesquisa de campo,envolvendo, dentre outras técnicas, a realização de grupos focais com jovens entre 18-24 anos, buscando compreender a dimensão simbólica dos bens de consumo (especificamenteas roupas de marcas) e os sentidos a eles atribuídos em contextos periféricos. A autora considera, também, a influência da mídia na difusão de estilos, sobretudo por meio de grifes esportivas. Como resultado, a pesquisa aponta a associaçáo entre o universo das grifes ou das "roupas de marca" com as celebridades, especialmente quando estas encarnam personagens das telenovelas e/ou fazem parte do mundo do esporte. Nesse sentido, a contribuição do texto, nesse Dossiê, é apontar que, apesar das novas mídias sociais, dos aplicativos e das novas formas de consumo, as telenovelas e as celebridades, sobretudo do mundo esportivo, ainda são importantes influenciadores e produtoras de mercado, reforçando mais uma vez as hipóteses da sociologia econômica, que existemdiversos tipos demercados econsumos plurais.

Por fim, e abordando especificamente as mídias, este Dossiê aborda jornais e jornalistas. $\mathrm{O}$ artigo de Jacques Mick explora o mercado de notícias a partir da imagem dos jornalistas e das empresas deste setor. $\mathrm{O}$ artigo analisa a disparidade entre os índices declinantes de confiança nas mídias jornalísticas enquanto permanece estável a credibilidade nos jornalistas no Brasil. O estudo recupera dados secundários de diferentes fontes sobre confiança na mídia jornalística no Brasil entre 1998 e 2018, indicando deterioração da credibilidade, e pesquisas recentes demonstrando que a confiança dos jornalistas como profissionais permanece acima da média. $\mathrm{O}$ artigo toma como elemento de análise surveys e entrevistas realizadas na cidade de Joinville/SC. Ainda que hajasuspeitas quanto às mídias jornalísticas em relação aos seus interesses e que suas açôes interfiramna qualidade da informação jornalística, permanece a confiança e o reconhecimento de que os jornalistas são peritos que se esforçam em prol do interesse público. 